\title{
Health Service Characteristics and Utilization in Calabar Metropolis, Cross River State, Nigeria
}

\author{
Ibor, Uguru Wisdom
}

Atomode, Tolu Isaac

\author{
Department of Geography, Federal University Lokoja, \\ P.M.B 1154, Lokoja, Kogi State, Nigeria \\ wisdomibor@yahoo.com, toluwaseisaac@gmail.com
}

Doi:10.5901/ajis.2014.v3n1p265

\begin{abstract}
This study examined health service characteristics and utilization in Calabar Metropolis, Cross River State, Nigeria. Data for the study were obtained from hospital records and survey of medical services in the selected hospitals. Ownership and Operational performance of these health facilities was determined using the inventory turnover ratio of the hospitals and the data obtained was analyzed using tables, simple percentages and multiple regression analysis. The result showed that 6 hospitals in the area were owned and operated by government, while 6 other hospitals were owned by private individuals or groups. The multiple regression analysis was used to determine the effects of number of beds to patients, number of doctors to patients and number of nurses/midwives to patients on access to health care facilities. The result indicated that $76 \%$ of access to medical facilities was explained by beds/patients ratio $\left(x_{1}\right)$, doctors/patients ratio $\left(x_{2}\right)$ and nurses/patients ratio $\left(x_{3}\right)$. The strength of contribution of each of the independent variables showed that doctors/patient ratio (0.508) made the greatest contribution to utilization of medical services. Next was nurses/patient ratio (0.253) and the least was bed/patients ratio (2.827). The study therefore revealed that bed/patients ratio, doctors/patient ratio and nurses/patient ratio are significant predictors of access to medical facilities. Based on the findings of the study, it was recommended that government and other sponsoring agencies should provide a more robust primary health care system with modern facilities and sufficient medical personnel to guarantee improved accessible health outcomes among the populace.
\end{abstract}

Keywords: Service Characteristics, Medical Facilities, Healthcare Choices, Utilization.

\section{Introduction}

A major concern of the World Health Organization $(\mathrm{WHO})$ is the provision of quality health care for everyone irrespective of varying levels of living. That is, whether in the advanced or poor countries, rural or urban, poor or rich; good health should be guaranteed by the governments of all countries. Health is often administered from health facilities which are categorized into; primary, secondary, and tertiary institutions. It is therefore the responsibility of governments, health planning authorities or groups to supply or locate health care facilities in order to achieve high accessibility which would enhance utilization and ultimately translate to good health status of the populace.

Health services utilization simply means the willingness of the would-be or potential patients to make the most of the services offered at a medical establishment. The utilization of health services is an important policy concern in most developing countries, reflecting both efforts to improve health outcomes and to make health services broadly accessible. Although many policy and research initiatives have focused on the need to improve physical access (lyun, 1983; Okafor, 2007), not enough is understood about what services and quality indicators affect health care choices, and why low levels of utilization persists among certain socioeconomic groups or geographic regions despite improved physical access (Ibor, 2010).

It is undoubtedly true that economic variables alone cannot explain health care utilization as the type of health services provided in a particular medical establishment is a significant determinant in decisions about outpatient visits (Ibor et al, 2011). The type of health services available to a population is an important factor in the choice of utilization. In particular, both the presence of specialized services and a broader service range make it more likely that patients choose a facility-based delivery.

Health facility utilization may be service specific, although certain dimensions of access may have little or no impact on outpatient visits, they may be important determinants of the use of other health services. Different health 
problems require certain services, so are many health facilities performing different functions. As Nigeria continues to face difficult trade-offs between health services and access, many health facilities are under-utilized because of the type of services provided, it will be important to deepen our understanding of how individuals make health care choices and the type of services they utilize (Adejuyigbe, 1977; Olujimi, 2003). It is against this backdrop that this study seeks to examine health service characteristics and utilization in Calabar Metropolis, Cross River, Nigeria.

\section{Study Area}

Calabar Metropolis comprises of both Calabar Municipality and Calabar South Local Government Areas of Cross River State, Nigeria. Calabar, the study area of this research is located between Latitude 4048 North and Longitude 8017 East. It covers an area of 210,936 sq km. According to the National Population Commission (2006), Calabar has a total population of 439,768 people, thus making it the most populous single city in the state owing largely to rural-urban and urban-urban migration. National population commission (2007) also revealed that there are about 74,580 households in the metropolis.

The geometric increase in the population of people in the city has met with a decrease in medical facilities in the city. Hospitals and clinics are not easily accessible to care seekers due to spatial inequalities and contradictions inherent in the urban distribution of services (Eni, 2012). The few available hospitals lack the necessary facilities and personnel. The old and new Calabar remain the same in terms of health care delivery. The population increase in the city would normally warrant new medical centers, up-grading of the existing facilities, location of health centers in hitherto un-served areas. The deplorable conditions of most public \& private health institutions and the type of services provided by these hospitals are the basis for this study.

\section{Method}

The data for the study were derived from hospital records and actual questionnaire surveys. Direct field observation was carried out, involving identification and survey of health services provided by sampled medical facilities in the study area. A sample was made from 12 hospitals in the city (See Table 1), using their outpatients and in-patients records. Accordingly, the following hospitals were identified: St. Lawrence Hospital (ward 3); Peace Medical Centre (ward 5); Mambo Clinic (ward 9); General Hospital (ward 1); Grace and Truth Maternity (ward 12); Ukpong Clinic (ward 4); University of Calabar Medical Centre (ward 1); Nigeria Navy Hospital (ward 5); Apex Clinic (ward 6); Immanuel Infirmary (ward 8); Mambo Clinic and Mission Hills (ward 9). Information on number of specialists and specialized services was derived from each health establishments. The doctor/patient ratio, nurse/midwife/patient ratio, bed/patient ratio, and other hospital related problems were obtained from these hospitals.

The analysis was therefore based on facility data from the catchment area of each hospital where the sample was drawn. The types of health services were measured in terms of size, profile and ownership status of hospitals. The inventory turnover ratio was applied by dividing the total number of hospital beds by the number of occupied beds. The multiple regression analysis was used in examining the total effect of the independent variable (number of beds to patients, number of doctors to patients and number of nurses/midwives) taken together on the dependent variable (utilization of health care facilities).

Table 1: Distribution of health care facilities in Calabar Metropolis.

\begin{tabular}{cllcl}
\hline S/n & \multicolumn{1}{c}{ Health care facility } & \multicolumn{1}{c}{ Location } & Ward & \multicolumn{1}{c}{ Rank } \\
\hline 1 & St. Lawrence Hospital & Hawkins by Edibe edibe & 3 & Secondary hospital \\
2 & Peace Medical Centre & Ergenton by Lagos street & 5 & Primary health centre \\
3 & Mambo Clinic & Atamunu street & 9 & Primary health centre \\
4 & General Hospital & Mary Slessor & 1 & Secondary hospital \\
5 & Grace \& Truth Maternity & Ekpo Abasi & 12 & Primary health centre \\
6 & UNICAL Medical Centre & Etta Agbor & 1 & Secondary hospital \\
7 & NN Hospital & Diamond Hill & 5 & Secondary hospital \\
8 & Apex Clinic & Asari Eso & 6 & Specialist hospital \\
9 & Immanuel Infirmary & Army Junction & 8 & Primary health centre \\
10 & Mission Hills & Ikot Nkebre & 9 & Primary health centre \\
11 & Teaching Hospital & EttaAgbor/Eastern Highway & 1 & Tertiary hospital \\
12 & Ukpong's Clinic & State Housing & 4 & Primary health centre \\
\hline
\end{tabular}

Source: Author's Field Survey 2013. 


\section{Results and Discussion}

\subsection{Analysis of Hospital Profile and Service Characteristics in Calabar Metropolis}

The study grouped functions of the studied hospitals into five categories according to the existing classification by Cross River State Ministry of Health as follows; General, Pediatric, Maternity, Specialized (short term) and Psychiatric and TB Hospitals (long term). Hospital records revealed that there is an average of 121 bed spaces for general consulting medical services; 200 for Pediatric; 144 for maternity; 67 for specialized medical services; and 11 for long term services such as orthopedic, etc. The majority of the hospitals in the area are short-term general and specialized hospitals. Only two hospitals have long-term facilities, namely General hospital, and University of Calabar Teaching Hospital (UCTH), accounting for 99 beds (see Table 2).

Lab test, X-ray tests and surgeries/deliveries per admission were inventoried. From the survey, specialized hospitals have the highest intensity of medical outputs, rendering all three services (Lab test, X-ray tests and surgeries/deliveries). General hospitals have a slightly higher intensity of services than the pediatric hospitals. Availability of other pharmaceutical services/supplies such as pharmaceutical stores, Radioisotopes, Scan, X-ray, Magnetic Resonance Imaging (MRI), Blood bank, others also exists in the sampled hospitals. The survey reveals that the University of Calabar Teaching hospital also takes the lead, rendering all of these services. General hospital renders all but MRI; while University of Calabar Medical Centre also performs all services except scanning.

Hospitals were further categorized based on ownership: government, Private, NGO/Institution and Community. From the 12 hospitals, 6 hospitals in the area are owned and operated by government (Federal and State alike); while, 6 other hospitals are owned by private individuals or groups. There were no community-own hospitals. From the analysis, general hospitals have the highest ratio of inventory per occupied bed apart from pediatrics. This fact could be explained by the low occupancy rates of these hospitals. Long-term hospitals have the lowest ratio, which reflects the high occupancy rates of these hospitals in the sample and the relatively low level of sophistication of medical equipment and inventory in maternity, psychiatric, and TB hospitals. However, almost all hospitals perform more than one service and therefore make it difficult to determine exactly which service had given rise to admission or bed ownership.

However, General Hospital also account for $20.4 \%$ of surgeries in the sample. Others, such as St. Lawrence Hospital do not perform surgery at all. In terms of accident emergency, a uniform ratio of 1:0 apply to all hospitals in the sample, however the magnitude of such accidents/emergency, proximity to the nearest hospital or clinic, income level, time of the accident among others may determine the kind of health facility to visit for such cases. Only three hospitals perform dialysis: they are General Hospital, UCTH and Nigerian Navy Hospital (NNH). Visual ambulance services were not performed by most of the hospitals accounting for a ratio of 0:9. Pharmacies and patent medicine outlets were also investigated in the study area. A functional and duly registered pharmacy exists in most of the hospitals to enhance access to drugs.

The survey on the types and numbers of hospital personnel shows that Doctors employed in the hospitals represent approximately $18.6 \%$ of both medical and administrative staff. Para medical personnel (nurses and midwives) in the survey comprised approximately $42.6 \%$, and overall medical personnel employed in the surveyed hospitals constitute $61.2 \%$ and the remaining $38.8 \%$ is administrative and technical personnel. The study identified two hospitals offering psychiatric services apart from the highly specialized psychiatric Hospital.

Table 2: Health Services and Number of Hospital Beds

\begin{tabular}{ccc}
\hline S/N & Service Type & No. of Beds \\
\hline 1 & General & 121 \\
2 & Pediatric & 200 \\
3 & Maternity & 144 \\
4 & Specialized & $67 \mathrm{~s}$ \\
5 & Long Term & 11 \\
\hline
\end{tabular}

Source: Author's Field Survey 2013.

\subsection{Reasons for Choice and Use of Hospitals}

Information on selection criteria for choice of hospitals is presented in Table 3 . The analysis shows that, $10.0 \%$ of the 
patients had no choice of hospital. However, $14.0 \%$ were referred to the particular hospital due to an emergency and this accounted for the most paramount reason for the choice of hospital. Free treatment for respondents themselves and or members of family was ranked as the second most frequent reasons for choosing a particular hospital accounting for $11.2 \%$. The third factor mentioned by respondents was closeness of the hospital to residence and good condition (10.8\% and $6.2 \%$ respectively) explaining proximity as a factor of accessibility to medicine in the study area. Acquaintance was the fourth factor mentioned (2.3\%) meaning that the perceived benefits of personal relations with medical personnel, or the expectation of preferential treatment and the evasion of possible harassment. While referral by a doctor played a critical role in the selection of specialized hospitals, the need for emergency attention was the paramount reason for choosing pediatric and general hospitals. Availability of experienced personnel accounted for $5.5 \%$ of the choice of maternity hospitals.

Good physical conditions were more frequently mentioned by patient's selecting maternity hospitals and accounted for $4.3 \%$. It is likely that in a non-urgent situation, particularly when the choice of maternity hospital is made several weeks in advance, comfort and amenities become very important criteria for making the decision. General patient's dissatisfaction with hospital services was considerably high. For example, $52.75 \%$ of the respondents indicated that they were completely dissatisfied with hospital services while $17.9 \%$ of them were less dissatisfied. Only about $12.6 \%$ of the 649 respondents reported complete satisfaction while 16.8\% expressed less satisfaction. In terms of hospital performance, patients utilizing Maternity hospitals had the most satisfied services as cited by $74.4 \%$ of the respondents. Such high satisfaction rating was attributed to less waiting time and doctor's urgent attention to care seekers.

The respondents were further asked to rank the hospitals based on six criteria: facility, services, food hygiene, and supply of pharmaceuticals access road and the professional qualifications of medical staff. Almost all respondents ranked the UCTH highest in all criteria except for food where they indicated are usually personal (from home). Therefore, the UCTH is observed to be highly favoured by all respondents except for what most of them who complained as poor access roads to the hospital. This can be attributed to the excluded location of the hospital in its permanent site, coupled with poor urban transport facilities in Calabar metropolis and very low car ownership ratio. Finally, the respondents were asked if they would recommend the hospital they used to other patients with similar medical problems. Overall negative answers were received in $73.6 \%$ of the cases examined. They generally believed that UCTH is a viable option aside from private hospitals whose cost they observed can be very high for medium and low income earners.

Table 3: Criteria for Choice of Hospital

\begin{tabular}{clcc}
\hline S/N & Reason for Choice of Hospital & Frequency & $\%$ \\
\hline 1 & Sent by the doctor & 40 & 6.2 \\
2 & Need of emergency aid & 91 & 14.0 \\
3 & Experienced personnel & 36 & 5.5 \\
4 & Free treatment & 73 & 11.2 \\
5 & Close to residence & 70 & 10.8 \\
6 & Medicines available & 20 & 3.1 \\
7 & Good maternity conditions & 28 & 4.3 \\
8 & Experienced personnel* & 35 & 5.4 \\
9 & Free treatment* & 51 & 7.9 \\
10 & Close to residence* & 40 & 6.2 \\
11 & Good conditions* & 15 & 2.3 \\
12 & Acquaintance & 65 & 10.0 \\
13 & Had no other choice & 36 & 5.5 \\
14 & Other reasons & 49 & 7.6 \\
& Total & 649 & 100 \\
\hline
\end{tabular}

Note: The same question was asked considering the patient's personal experience or the experience recommendations of their family member. Those questions are marked with an asterisk.

Source: Author's fieldwork, 2013.

\subsection{Accessibility Constraints to Health Care Utilization}

The analysis in Table 4 shows that $20.8 \%$ of the respondents indicated transport difficulty especially during emergency as the constraints encountered in accessing health care. This can be ascribed to the poor access roads to most of the 
hospitals coupled with low car ownership by the respondents. Moreover, problems of affording medicines accounted for $15.9 \%$ of the sample and hospital bills payment for $18.5 \%$. The fact that high level of poverty persist among the populace in the study area explained why a total of $34.4 \%$ of the respondents find it difficult to either pay for prescribed drugs or pay their hospital bills. The problems of getting prescribed medicines and specialists respectively accounts for $16.2 \%$ and $13.9 \%$ of the constraints to heath care accessibility. The explanation for these problems could not be farfetched from the non-availability of most of the prescribed drugs as well as a good number of specialists to handle all cases of ailment in the hospitals. Others problems accounted for $2.9 \%$. However, $12.6 \%$ of the respondents declared not to have any constraints in accessing health care. This represents the few advantaged people who earned a considerable high income that could possibly afford their health needs.

Table 4: Constraints to Health Care Accessibility

\begin{tabular}{clcc}
\hline S/N & Accessibility Constraints & Frequency & $\%$ \\
\hline 1 & Transportation difficulty & 135 & 20.8 \\
2 & Cost of Drugs & 103 & 15.9 \\
3 & Payment of Treatment bill & 120 & 18.5 \\
4 & Difficulty in getting medicines & 105 & 16.2 \\
5 & Difficulty in finding specialists & 85 & 13.9 \\
6 & None & 82 & 12.6 \\
7 & Other & 19 & 2.9 \\
& Total & 649 & 100 \\
\hline
\end{tabular}

Source: Author's Field Survey, 2013.

\subsection{Effects of Medical Resource and Hospital Facilities on Utilization}

Multiple Regression analysis was used in examining the total effect of the independent variable (number of beds to patients, number of doctors to patients and number of nurses/midwives) taken together on the dependent variable (access to health care facilities). The result shows that a combination of the independent variables in predicting access to medical facilities yielded a multiple regression coefficient $(R)$ of 0.762 and a square multiple regression coefficients $\left(R^{2}\right)$ of 0.581 . This suggests that the bed/patients ratio doctors/patient ratio and nurses/patient ratio are significant predictors of access to medical facilities. A multiple R2 of 0.581 implies that the independent variables explain $58.1 \%$ of the variance of access to medical facilities.

The analysis of variance (ANOVA) was used to test the significance of the overall effect of the independent variables on the dependent variable. The result of this analysis is contained in Table 3. The regression mean square is 1693. 112 and the residual mean square is 10.275 , hence the F-value is 164.786 and this is significant at 0.05 level. Hence, the three independent variables significantly explain utilization of health care facilities. The regression equation for the relationship between the dependent variable (utilization of health care to medical facilities and each of the independent variables is given as:

\section{-0.054 (Beds/patient ratio) +00.253 (nurses/patient ratio) +0.508 (doctors/patient ratio) (1)}

The test of each regression weight shows that the standardized regression weight ranged from -0.054 to 0.508 ,while the t-ratio range from -1.512 to 5.60 . The strength of contribution of each selected factors are ranked according to the product of standardized regression coefficients (Beta). From these results, doctors/patient ratio (0.508) made the greatest contribution to access to medical facilities, next is nurses/patient ratio $(0.253)$, while beds/patient ratio $(-0.054)$ the least contribution to patronage of health facilities. This result shows that the beta weight of one independent variable (bed/patient ratio, -0.054 ) was not statistically significant at 0.05 level.

The results further implies that a unit increase in doctors/patient ratio holding every other variables constant, will result in 0.508 percent unit increase in utilization of health care to medical facilities; also a unit increase in nurses/patient ratio holding other variables constant, will result in 0.253 or 35.3 percent unit increase in utilization of health care to medical facilities. However, predictor variable with negative sign indicate an inverse relationship with access to medical facilities, for instance, a unit increase in beds/patient ratio holding every other variables constant, will result in 0.054 or 0.54 percent unit decrease in access to healthcare delivery centres. The implication is that when the independent 
variables are considered individually, only two variable (nurses/patient ratio, 00.253; and doctors/patient ratio, 0.0508) significantly contributed to access to medical facilities (see Table 5).

Table 5: Multiple Regression Analysis of Independent Variables and Access to Medical Facilities

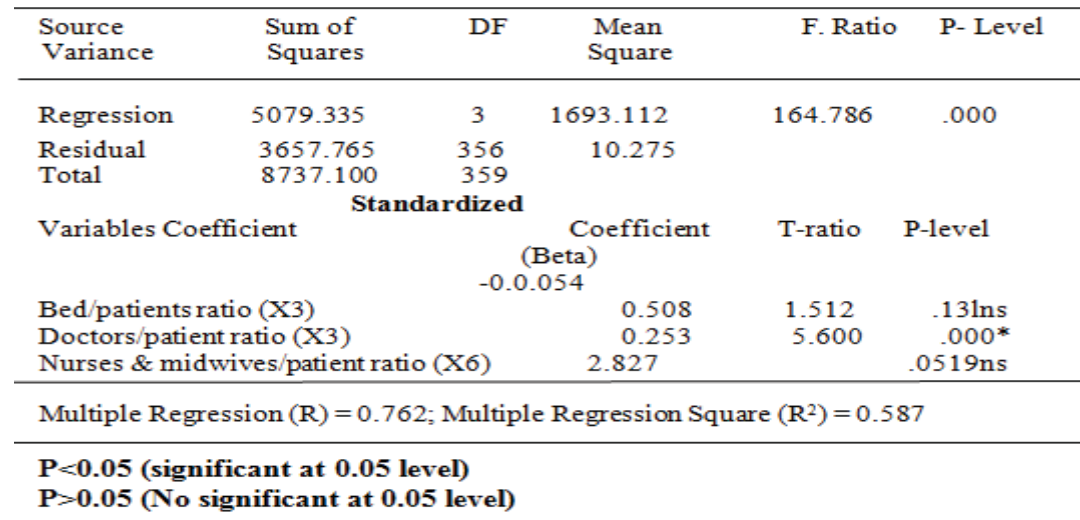

\section{Conclusion}

The study has shown that the size and status of hospitals determine the quality and quantity of the facilities and services provided. The hospital studied encompassed almost all types of hospitals currently operating in Calabar metropolis, varying in size, type, ownership status, and geographical location. Several findings on hospital performance and operational indicators are worth mentioning. The distribution of specialist doctors in the study area shows that health facilities and services are not adequate to demands of care seekers. The study also revealed an astonishing ratio of medical personnel to patients. These ratios account mostly for the poor services and inaccessibility of medical care, leading to unbearable waiting time. The study also observes that, specialized hospitals have the highest intensity of medical output, leading in all the three parameters such as lab tests X-ray test and Surgery per admission. This is followed slightly by General Hospital, Pharmaceutical store services is the most highly rendered service. A high percentage of the medical personnel are employed by Teaching and General Hospitals. However, the facilities at both UCTH and other hospitals still require comprehensive up-grade to meet modern challenges in healthcare delivery. Accessibility constraints in the area were identified as transportation difficulty, money paid for service, difficulty in getting needed drugs, high cost of medicine among others. Based on the gaps revealed through the findings of this study, the study recommends that the authority concern should introduce a more robust primary health care system with modern facilities and sufficient medical personnel to guarantee quality and accessible health outcomes among the populace.

\section{References}

Adejuyigbe, O. (1977). Providing Health care in the rural areas of Western States of Nigeria. Nigeria Medical Journal, 4 (1), 6-12.

Eni, D.D., Ibor, U.W., Ojong, O.E. and Ogundele, F.O. (2012). Location, Distribution and Utilization of Insecticide Treated Nets (ITNs) in Cross River State, Nigeria. International Journal of Humanities and Social Science. Vol. 2 No. 2, pp 249-253.

Ibor, U. W., Anjorin, O. A, Ita, A. E, Otu, M. A and Bassey, T. I (2011). Utilization of Antenatal Care in Ibadan North Local Government Area, Oyo State, Nigeria. Trends in Medical Research 6(4): 273-280 ISSN 1819-3587.

Ibor,U.W. Ojong, E.O. and Eni, D.D. (2010). Distribution and Utilization of Health Facilities in Calabar Metropolis, Annals of Humanities and Development, Vol. 2 (10) pp. 346-347.

Iyun, B.F. (1983). Factors Influencing Patronage of Hospitals in Ibadan City in L.K. Jeje (ed), The Nigerian Geojournal, Vol. 26, Nos. 1\& 2, June \& December 1983.

Joseph, A.E. and Philips, D.R. (1984). Accessibility and Utilization: Geographical Perspective on Health Care delivery, New York, Happer and row Publishers.

Okafor, S.I. (2007). Location, Distribution and Question of Justice. An Inaugural Lecture. Ibadan: University of Ibadan Press.

Olujimi, J.A. (2003). Patronage Pattern of Rural Dwellers to Health facilities in Owo Region Nigeria, Unpublished Ph.D Thesis, Dept of Urban and Regional Planning, Federal University of Technology, Akure, pp. 265-270.

National population commission (2007). Federal Republic of Nigeria Official Gazette No.24 Vol.94 Lagos Nigeria. 